\title{
Circumferential esophageal endoscopic submucosal dissection thanks to the tunnel + clip strategy: four tunnels to facilitate the procedure
}

A 66-year-old man was referred to our endoscopy unit for endoscopic submucosal dissection (ESD) of a superficial circumferential adenocarcinoma developing over by severe Barrett's esophagus.

After marking the distal and proximal margins ( $\mathbf{F i g . 1}$ ), we proceeded to make proximal and distal circumferential incisions using a T-type HybridKnife (Erbe Medical, Tübingen, Germany) following an injection of glycerol solution ( $\triangleright$ Fig.2a). Next, we created two tunnels facing each other ( $\mathbf{F i g . 2} \mathbf{b}$, $\triangleright$ Video $\mathbf{1}$ ). Then, the scope was withdrawn and a Resolution clip (Boston Scientific, Marlborough, Massachusetts, USA) was inserted into the operative channel and attached to a $250 \mathrm{~cm}$ length of nonabsorbable suture wire (Péters Surgical, Bobigny, France) that had been wound into a U-shape. The scope was reinserted with the wire in parallel. The clip grasped the edges of the first two tunnels ( $\bullet$ Fig. $2 \mathbf{c}$ ). The third tunnel was easily created as exposure of the submucosal layer was very clear due to constant traction using plastic $11 \mathrm{~g}$ Kocher forceps (nessicare dressing kit; LCH Medical Products, Paris, France) grasping the external side of the wire ( $\triangleright$ Fig. $2 \mathbf{d}$ ). Tunneling was made from the first tunnel anterior bank to the second tunnel anterior bank with con-

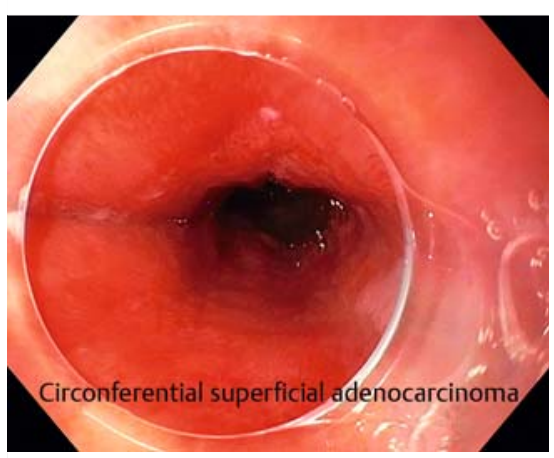

- Fig. 1 Circumferential superficial esophageal adenocarcinoma.

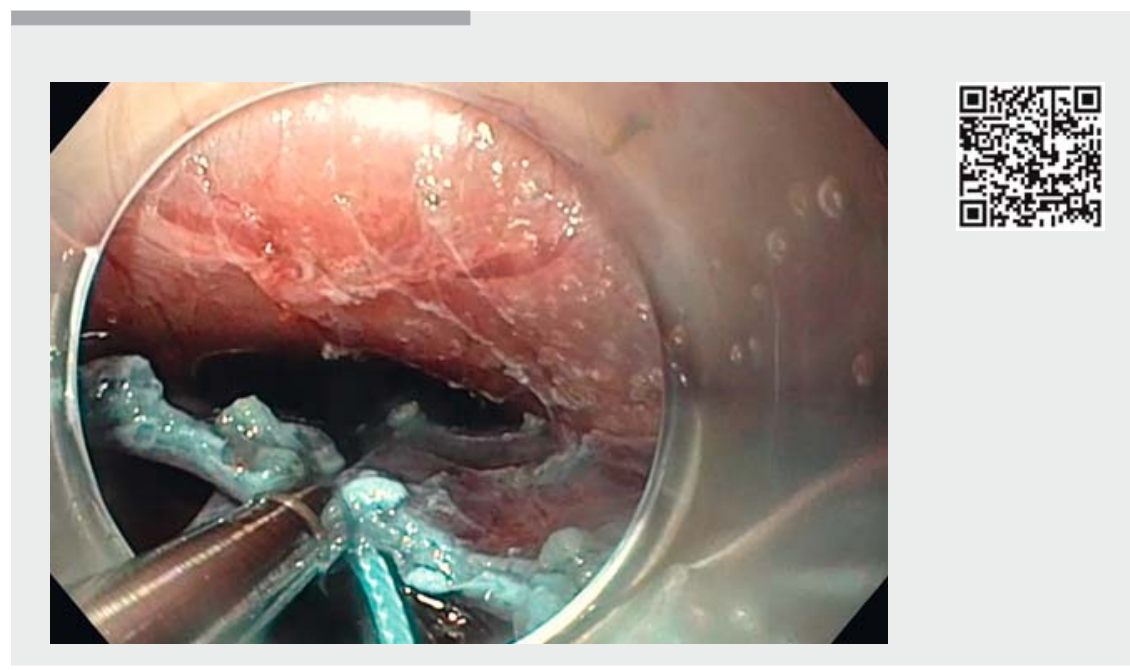

$\checkmark$ Video 1 Circumferential esophageal endoscopic submucosal dissection of a superficial circumferential adenocarcinoma using a four-tunnel + clip strategy.
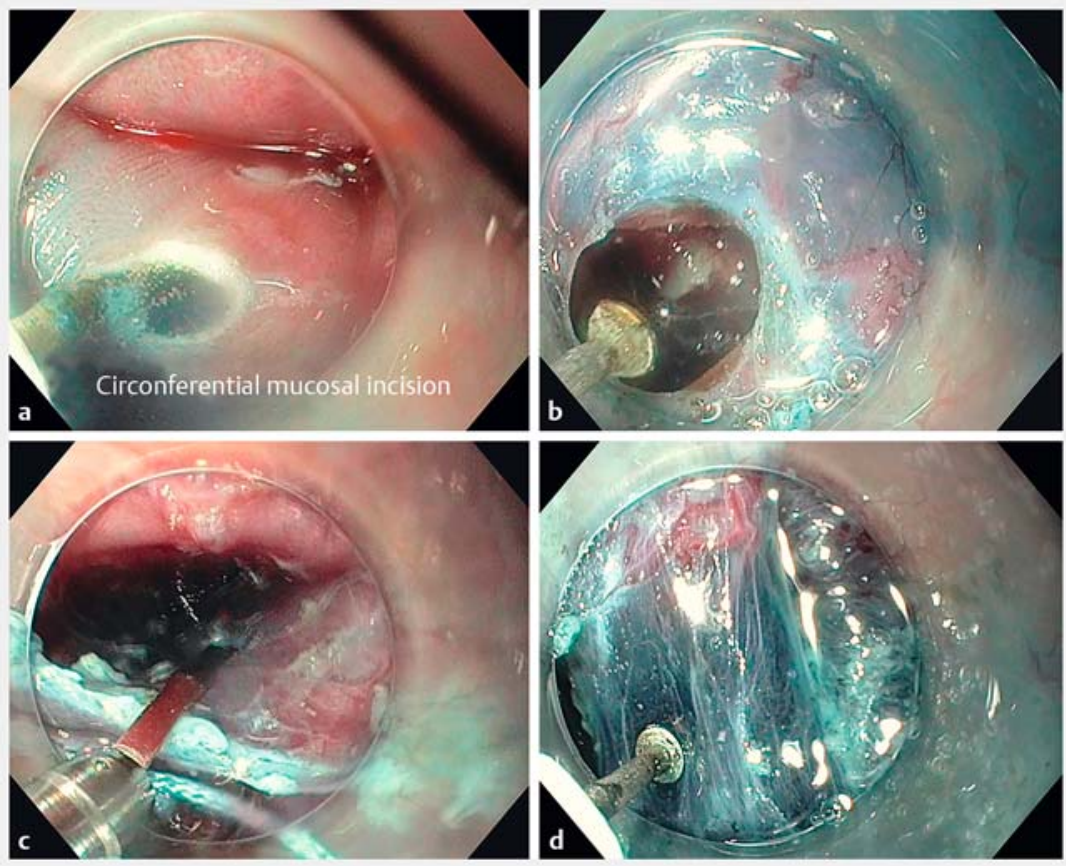

- Fig. 2 The tunnel + clip strategy. a Incision of the proximal margin after injection of a glycerol solution. b Distal extremity of the first tunnel. c Clip grasping the mucosal flaps of the first two tunnels. $\mathbf{d}$ Good exposure of the submucosal layer while creating the third tunnel. 


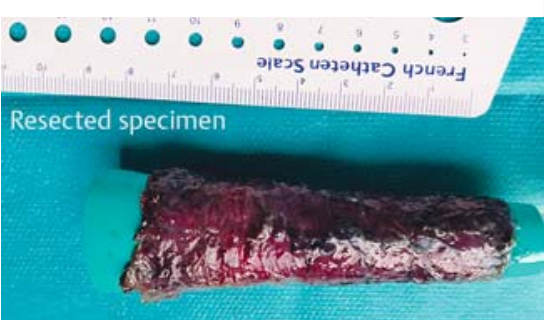

- Fig. 3 En bloc circumferentially resected specimen displayed over a plastic tube.

stant perfect exposure of the submucosal layer due to the traction. Keeping the countertraction constant, a fourth tunnel was created at the posterior face to join the dorsal banks of the first two tunnels. A $12 \mathrm{~cm}$ circumferential en bloc resection specimen was extracted in 170 minutes ( Fig. 3).

The thinness of the esophageal wall and the narrow diameter make scope manipulation difficult and increase the risk for perforations; as such, esophageal ESD is a technically challenging and high risk procedure. Superficial esophageal cancers (circumferential or almost circumferential) require 360-degree resection to obtain an en bloc specimen with clear margins. Good exposure of the submucosal layer is key to performing dissections safely and quickly. Moreover, damage to the muscle layer may be caused by postESD esophageal stenosis [1]. The twotunnel strategy has been reported for circumferential esophageal ESD. However, without the addition of traction, the procedure, particularly the final step, can be very technically challenging and risky. This may be due to the rotation of the specimen, which considerably reduces the visible working area, and its inversion into the stomach lumen. Tunnel dissection facilitates esophageal ESD because it allows for perfect exposure of the submucosal layer [2]. The addition of clip traction at the end of the two tunnels allows for circumferential ESD to be performed with four consecutive tunnels.

We previously described our tunnel + clip method, which combines clip-with-line and tunneling, as a method that could facilitate the esophageal ESD strategy [3]. This method facilitates dissection by allowing soft strain until the last fibers of the submucosa, and particularly the edges of the tunnel, are dissected. We adapted this method for circumferential esophageal ESD. We have performed this strategy in 10 patients to date, without any perforation and with fast dissection speed $\left(30 \mathrm{~mm}^{2} / \mathrm{min}\right)$. With the help of clip traction, the four-tunnel strategy could become the standard strategy for circumferential esophageal ESD.

Endoscopy_UCTN_Code_TTT_1AO_2AG

\section{Competing interests}

None

The authors

Marion Schaefer ${ }^{1}$, Jérémie Albouys ${ }^{1}$, Aurélie Charissoux ${ }^{2}$, Denis Sautereau', Romain Legros $^{1}$, Mathieu Pioche ${ }^{3}$, Jérémie Jacques ${ }^{1,4}$

1 Service d'Hépato-gastro-entérologie, $\mathrm{CHU}$ Dupuytren, Limoges, France

2 Service d'Anatomopathologie, $\mathrm{CHU}$ Dupuytren, Limoges, France

3 Service d'Hépato-gastro-entérologie, Hôpital Edouard Herriot, CHU Lyon, France

4 BioEM, UMR 7252, CNRS, Limoges

Corresponding author

\section{Marion Schaefer}

Service d'Hépato-gastro-entérologie, CHU Dupuytren, 2 Avenue Martin Luther-King, 87042 Limoges, France

Fax: +33-5-55058733

mrn.schaefer@gmail.com

\section{References}

[1] Miwata T, Oka S, Tanaka S et al. Risk factors for esophageal stenosis after entire circumferential endoscopic submucosal dissection for superficial esophageal squamous cell carcinoma. Surg Endosc 2016; 30: 40494056

[2] Pioche M, Mais L, Guillaud O et al. Endoscopic submucosal tunnel dissection for large esophageal neoplastic lesions. Endoscopy 2013; 45: $1032-1034$

[3] Jacques ], Legros R, Rivory J et al. The "tunnel + clip" strategy standardised and facilitates oesophageal ESD procedures: a prospective, consecutive bi-centric study. Surg Endosc 2017; 31: $4838-4847$

\section{Bibliography}

DOI https://doi.org/10.1055/a-0733-3607

Published online: 17.10.2018

Endoscopy 2018; 50: E350-E351

(c) Georg Thieme Verlag KG

Stuttgart · New York

ISSN 0013-726X

\section{ENDOSCOPY E-VIDEOS}

https://eref.thieme.de/e-videos

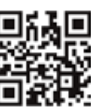

Endoscopy E-Videos is a free access online section, reporting on interesting cases and new

techniques in gastroenterological endoscopy. All papers include a high quality video and all contributions are freely accessible online.

This section has its own submission website at https://mc.manuscriptcentral.com/e-videos 